\title{
Dynamic characteristics of a water resource structure in an urban ecological system: structure modelling based on input-occupancy-output technology
}

\author{
Qiang Xiao ${ }^{\mathrm{a}, \mathrm{b}}$, Dan $\mathrm{Hu}^{\text {b, * }}$ \\ ${ }^{\text {a } C h o n g q i n g}$ College of Arts and Sciences, Chongqing 402160, China \\ b State Key Laboratory of Urban and Regional Ecology, Research Center for Eco-Environmental Sciences, Chinese Academy of Sciences, Beijing 100085, China
}

\section{A R T I C L E I N F O}

\section{Article history:}

Received 1 September 2014

Received in revised form

5 January 2016

Accepted 22 February 2016

Available online 10 March 2016

\section{Keywords:}

Human activities

Ecological input-occupancy-output table

Blue water

Grey water

\begin{abstract}
A B S T R A C T
China is suffering from serious water problems that have been attributed to economic growth. We therefore aimed to evaluate socioeconomic activities in the City of Chongqing that affect water demand and pollutant discharge with the goal of assessing ecological input-occupancy-output table technology. Chongqing's water resources are the subject of the study, which investigates the socioeconomic and ecological distribution of water utilization. Our data reveal that the total water demand in the City of Chongqing is 576.76 billion $\mathrm{m}^{3}$. Most of the water is consumed by primary industries (37\%), followed by secondary industries (42\%), tertiary industries (4\%), and households (17\%). The total grey water footprint of the city is 24.224 billion tons. This finding suggests that the utilization structure of water in this region is closely linked to economic development. Because utilization structure is an important factor affecting water consumption, addressing this structure is the first measure in regulating water consumption and avoiding water shortages. An effective system incorporating a management policy for industrial water utilization is one of the primary methods by which conflicts of water resource allocation can be avoided. The effective allocation of water resources can be realized via the fair distribution of water resources among different regions and users, which guarantees sustainable utilization. Our study suggests that if the social water system is to be effectively and scientifically regulated, we must control excessive development and utilization of water resources and address the ecological and environmental issues caused by socioeconomic water consumption exceeding ecological water utilization.
\end{abstract}

(C) 2016 Elsevier Ltd. All rights reserved.

\section{Introduction}

The utilization of water resources by humans can interfere with the natural hydrological cycle, and the intensity of human water use in recent years is unprecedented. The excessive use of water resources has led to a myriad of problems, including water shortages, water pollution, and ecosystem degradation. In addition to using water as a material resource for consumption, humans regard the natural water system as a waste assimilation system (Aviso et al., 2011; Cao et al., 2015). The sharp rise in the discharge of industrial and domestic wastewater has exacerbated water pollution, leading to the degradation of ecosystems in many regions around the world (Bernardo, 2014; Bortolini et al., 2014).

\footnotetext{
* Corresponding author. Tel./fax: +86 1062849199.

E-mail addresses: xiaoqiang7598@126.com (Q. Xiao), hudan@rcees.ac.cn (D. $\mathrm{Hu})$.
}

China initiated water demand management in the 1970s and has, to some extent, achieved the anticipated results regarding water conservation, water price leverage, norm management, gross amount control, water rights allocation, and changing societal attitudes toward water conservation (Carballo Penela and Sebastián Villasante, 2008; Chen and Chen, 2010; Chen and Cao, 2013). However, the trend in water shortage, water pollution, and water system ecological degradation has not been controlled, primarily because humans fail to understand the flow patterns and the mechanism of water evolution in a socioeconomic system (Chang et al., 2010; Chen and Chen, 2011). To achieve regulation and control of a water circulating system, to safeguard the stability of the natural water circulating system, and to reduce the external environmental factors limiting water resource development and utilization, it is necessary to comprehensively understand the basic structure, circulating process, driving mechanism, and evolutionary pattern of water circulating systems and to scientifically study the 
evolution of the water resource within the socioeconomic system (Chang et al., 2010; Zheng et al., 2014).

The concepts of blue water (or special water, i.e., surface water and groundwater), green water (or general water, i.e., atmospheric water available for direct utilization by ecological and economic systems), and grey water have been developed over the past few decades. On a theoretical basis, however, scholars now suggest the use of a water resource allocation system for the unified allocation of special and general water resources (Chen and Chen, 2011; Chen et al., 2014). As the quantity and quality of a water resource are inseparable attributes, quantity management must be integrated with quality management to achieve total scientific management of the water resource (Cao et al., 2014a; Chen et al., 2010). To ensure a beneficial cycle and sustainable use of the resource, the water supply, water utilization, and water drainage pollution prevention must be managed in parallel. To this end, researchers have studied dual water supply, environmental flow, and water quality and quantity in terms of total quality and overall quantity control based on a water resource allocation model (Cheng et al., 2006; Dias et al., 2014; Dongjing et al., 2005).

In water system ecology, the water cycle structure ensures its function, and water cycle function is the basis of its structural regulation; hence, water cycle structure is the result of functional evolution and is associated with the direction and process of the next cycle.

This study focuses on structural analysis to identify the factors that ensure the integration of water cycle efficiency and function (Druckman and Jackson, 2009; Duarte et al., 2002). The structural study of a water cycle includes various components of a society's water cycle, including water supply, water utilization, and water drainage (Zheng et al., 2014). It is examined from the perspective of harmony between humans and nature required for the equitable distribution of water utilization and ecological sustainability necessary for a society's economy (i.e., the quantity of water in a natural system that is available for direct utilization by humans-traditionally, the special water resource), which is the fundamental focus and starting point for studies of the water cycle (García Morillo et al., 2015; Grêt-Regamey and Kytzia, 2007; Guan et al., 2011). The water consumption utilization structure is closely associated with the level of economic development, just as the industrial structure in a region is associated with that region's level of economic development; hence, it is an important factor related to water consumption and water shortage (Cao et al., 2014b). Thus, adjusting the water consumption utilization structure is a preferred technique for substantial water savings and solving water resource shortages. The water drainage structure is associated with water utilization structure and is a direct contributor to water pollution and water quality deterioration (Guan and Hubacek, 2008). The input-output table is a standard method for the analysis of water cycle structure.

Human activities require various environmental loads to produce goods and services (Jeswani and Azapagic, 2011; Miao et al., 2015). Environmental loads accrue based on the input-output of water as well as the production and consumption of materials for human activities. The demand for water and materials can represent a source of environmental load, and the balance of supply and demand can be used to establish the input of water and materials on the upstream side of the production and consumption process (Cao, 2012; Jenerette et al., 2006; Jiang and Tan, 2013). Features of productivity and consumption can define the form of environmental loads and wastewater (Fig. 1).

In the present work, we have used Chongqing as a case study. We first introduce a methodological framework for the analysis of an ecological input-occupancy-output table and present an estimation of the blue water and grey water footprints. We then select a water resource structure in an urban ecological system based on the ecological input-occupancy-output technology and further examine the blue water and grey water components. This is followed by a discussion of the consumption structures of blue and grey water footprints, the relationship between consumption demand and the blue and grey water footprints, and the relationship between water footprint and water resource consumption. Our ultimate conclusion is that effective industrial water resource administrative policies and systems are essential for solving problems involving water resource allocation. Reasonable industrial water allocation that provides equitable distribution among water users from different industries is needed to guarantee the sustainable utilization of water resources.

\section{Methods}

\subsection{Ecological input-occupancy-output table}

Classical input-output technology fails to reflect production factors such as natural resources and capital. Xikang (2000) found that natural resources, such as arable land, play an important role in grain production in prediction studies of grain output; however, this role was not indicated in traditional input-output models. This led to the development of the input-occupancy-output model (Xikang, 2000). This model is characterized by the relation between inputs and outputs as well as the quantitative relation between occupancy and output as well as occupancy and input. Occupancy is the basis of the production process. Input-occupancy-output analysis is characterized by an integrated investigation and analysis of system flow and inventory occupancy. Thus, a new model for the total consumption coefficient that takes occupancy into consideration has been formulated (Liang et al., 2010; Liang and Zhang, 2012). The ecological input-occupancy-output table is shown in Table 1.

To account for emissions and resources in an economic system based on a network model, the economic input-occupancy-output table is extended to an ecological input-occupancy-output table that covers both economic (i.e., currency) and ecological flows within and across the boundary of the economy (Lin, 2009). As illustrated in Table 1, the extended table can be divided into two parts: an economic table consisting of currency values for intra- and inter-sectoral product flows $\left(Q_{1}\right)$, final use flows $\left(\mathrm{Q}_{2}\right)$, and nonindustrial economic input flows $\left(\mathrm{Q}_{3}\right)$; and an ecological table consisting of the entrance $\left(Q_{4}\right)$ or departure $\left(Q_{5}\right)$ of ecological endowments in terms of conventional and systems ecological indicators. The external environmental inputs are the primary resources and emissions exogenous to the economy; all imported inputs are economic products divided into domestic intermediate-use categories.

Because the existing input-output table fails to include occupancy (i.e., it fails to reflect occupancy of ecological capital), it presents the illusion that the total output of all sectors is determined by the final demand vector. In fact, the quantity of natural resources and ecological capital occupied by all sectors is not assured and the calculated total output of all sectors cannot be determined, which leads to a series of ecological problems. Accordingly, the ecological input-occupancy-output analysis provides a more realistic approach compared to a standard input-output analysis (Liu et al., 2009).

\subsection{The algorithm}

The result of the ecological input-occupancy-output modelling procedure is equivalent to that of the conventional ecological input-output analysis where a direct emission coefficient is 


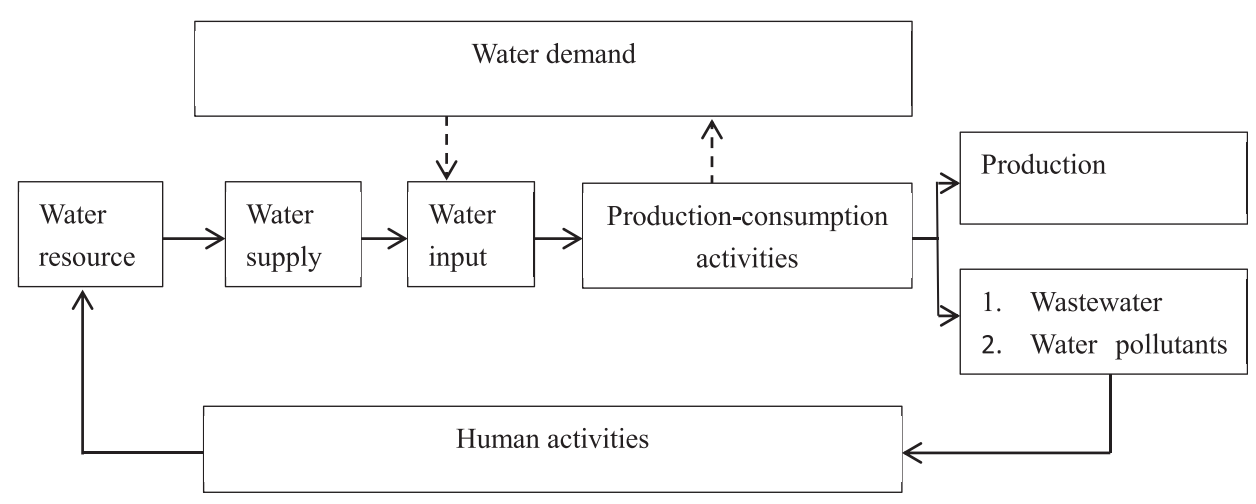

Fig. 1. Environmental load with human activities in water flow.

assigned as the local emission divided by the total output; the total emission coefficient based on final demand is then obtained as the direct emission coefficient multiplied by the Leontief inverse by expressing the total output as a function of final demand. The essential difference is that the embodiment of ecological input-occupancy-output modelling based on sectoral biophysical balance represents the total product, whereas the total emission coefficient of the ecological input-occupancy-output analysis is based on responsibility allocation and only captures final demand (Chen et al., 2002).

As in conventional input-occupancy-output studies, it is assumed that (a) the embodied resource and emission intensities are equal for all commodities from the same industrial sector; (b) the storage has the same embodied resource and emission intensities as the commodities produced in the current year; and (c) the imported commodities have the same embodied resource and emission intensities as domestic commodities.

\subsubsection{Blue and grey water footprints}

The water footprint includes green water (i.e., general water resources, namely atmospheric water available for direct utilization by the ecological and economic systems) and blue water (i.e., special water resources, namely surface water and groundwater resources); the green and blue water footprints are the result of the consumption of these respective waters in water resource utilization, whereas the grey water footprint is the result of wastewater discharge. Green and blue water footprints are associated with variations in the water resource; the grey water footprint is related to variations in the quality of the water resource.
The present study focuses on the blue and grey water footprints, which are based on water supply and drainage data from various industries; the green water footprint is not considered here. The blue water footprint includes actual water consumption, which is comprised of domestic water use, and virtual water consumption, which is comprised of indirect water use due to domestic and governmental consumption.

Domestic water consumption is determined by the water consumption coefficient, which is calculated based on the data for the corresponding year provided in the China Water Resource Communiqué.

Virtual water consumption is calculated by the formula

$\mathrm{VWC}_{j}=r_{\mathrm{co}, j} \times P_{j}$,

where $\mathrm{VWC}_{j}$ is the virtual water consumption $\left(\mathrm{m}^{3}\right)$ by product $j ; r_{\mathrm{co} j}$ is the total water consumption coefficient by product $j\left(\mathrm{~m}^{3} / \mathrm{CNY}\right.$ $10,000)$; and $P_{j}$ is the quantity of product $j$ consumed (CNY 10,000).

To calculate the grey water footprint, the wastewater discharge and pollutant concentration are taken into consideration, along with the water quality standard and background pollutant content. In this study, chemical oxygen demand (COD) was used as the specific pollutant to analyze the grey water footprint, which was calculated as follows:

$\mathrm{WF}_{\text {grey }}=\frac{L}{1000\left(c_{\max }-c_{\text {nat }}\right)}$,

where $\mathrm{WF}_{\text {grey }}$ is the grey water footprint $\left(\mathrm{m}^{3}\right) ; L$ is the pollution load (mg); $\quad c_{\max }$ is the maximum permissible pollutant

Table 1

The ecological input-occupancy-output table.

\begin{tabular}{|c|c|c|c|c|c|c|c|c|}
\hline & & \multicolumn{4}{|c|}{ Intermediate use } & \multicolumn{3}{|l|}{ Final use } \\
\hline & & Sector 1 & Sector 2 & Sector 3 & Sector $n$ & Consumption & Capital formation & Other uses \\
\hline Intermediate inputs & $\begin{array}{l}\text { Sector } 1 \\
\text { Sector } 2 \\
\text { Sector } 3 \\
\text { Sector } n\end{array}$ & & & $\mathrm{Q}_{1}$ & & & $\mathrm{Q}_{2}$ & \\
\hline Non-industrial economic inputs & Wages, taxes, surplus, etc. & & & $\mathrm{Q}_{3}$ & & & & \\
\hline Occupancy & $\begin{array}{l}\text { Water } \\
\text { 1. Surface water } \\
\text { 2. Groundwater } \\
\text { Recycled water }\end{array}$ & & & $\mathrm{Q}_{4}$ & & & & \\
\hline Occupancy & $\begin{array}{l}\text { Wastewater discharge } \\
\text { 1. } \mathrm{COD} \\
\text { 2. } \mathrm{NH}_{3}-\mathrm{N}\end{array}$ & & & $\mathrm{Q}_{5}$ & & & & \\
\hline
\end{tabular}


concentration $(\mathrm{mg} / \mathrm{L})$; and $c_{\text {nat }}$ is the background pollutant concentration of the water body in its natural condition $(\mathrm{mg} / \mathrm{L})$.

Calculation of the pollution load is based on two factors: the discharge of domestic wastewater and commodity consumption. In the case of domestic wastewater discharge, the formula is

$L_{\mathrm{d}}=1000 \mathrm{WW}_{\mathrm{d}} \times c_{\mathrm{w}, \mathrm{d}}$,

where $L_{\mathrm{d}}$ is the pollution load resulting from the discharge of domestic wastewater; $\mathrm{WW}_{\mathrm{d}}$ is the domestic wastewater discharge $\left(\mathrm{m}^{3}\right)$; and $c_{\mathrm{w}, \mathrm{d}}$ is the specific pollutant concentration $(\mathrm{mg} / \mathrm{L})$ in domestic wastewater to be determined by statistics obtained from the China Environment Yearbook.

The calculation of pollution load as a result of commodity (service) consumption is based on the virtual water discharge as follows:

$L_{j}=1000 \mathrm{VWW}_{j} \times c_{\mathrm{w}, j}$,

where $L_{j}$ is the pollution load resulting from the discharge of commodity consumption; $\mathrm{VWW}_{j}$ is the virtual water discharge $\left(\mathrm{m}^{3}\right)$ in an industry $j ; c_{w, j}$ is the specific pollutant discharge concentration in an industry $j$; and COD is the specific pollutant under study. The industrial product is determined based on the statistics provided in the China Environment Yearbook and on the agricultural product, while the tertiary industry is determined based on the specific pollutant discharge concentration.

For simplicity, the following modification to the calculation of grey water footprint was used in this article:

$\mathrm{WF}_{\text {grey }}=\frac{V_{\mathrm{effl}} \times\left(c_{\mathrm{effl}}-c_{\text {nat }}\right)}{c_{\max }-c_{\text {nat }}}$,

where $W_{\text {grey }}$ is the grey water footprint $\left(\mathrm{m}^{3}\right)$; $c_{\text {effl }}$ is the wastewater discharge concentration $(\mathrm{mg} / \mathrm{L}) ; V_{\text {effl }}$ is the wastewater discharge volume $\left(\mathrm{m}^{3}\right) ; c_{\max }$ is the maximum permissible pollutant concentration $(\mathrm{mg} / \mathrm{L})$; and $c_{\text {nat }}$ is the background pollutant concentration of the water body in its natural condition $(\mathrm{mg} / \mathrm{L})$. The number of freshwater resources used to absorb wastewater loads was obtained by comparing the wastewater concentration with the maximum acceptable concentration.

The conversion coefficient $k_{j}$ is defined as $k_{j}=\left(c_{\text {effl }}-c_{\text {nat }}\right) /\left(c_{\max }-c_{\text {nat }}\right)$, and the formula for the indirect grey water footprint is

$\mathrm{WF}_{\text {indirect-grey }}=k_{j} \times \mathrm{VWF}_{j} \times r_{\mathrm{d}, j}$,

where $\mathrm{WF}_{\text {indirect-grey }}$ is the indirect grey water footprint $\left(\mathrm{m}^{3}\right) ; \mathrm{VWF}_{j}$ is the indirect wastewater discharge $\left(\mathrm{m}^{3}\right)$ in an industry $j$; and $r_{\mathrm{d}, j}$ is the indirect water consumption coefficient of an industry $j\left(\mathrm{~m}^{3} / \mathrm{CNY}\right.$ 10,000).

\subsubsection{External water footprint and extra water footprint burden}

Interregional commodity (service) trade results in the flow of virtual water and virtual water discharge between regions. The formula for the net inflow of virtual water is

$\mathrm{VWI}_{j}=r_{\mathrm{co}, j} \times P_{j, \text { net,imp }}$,

where $\mathrm{VWI}_{j}$ is the net inflow of virtual water in an industry $j$ and $P_{j, \text { net,imp }}$ is the net import volume (CNY 10,000) of the commodity (service) in an industry $j$.

Similarly, the net inflow of virtual water discharge is calculated
$\mathrm{VWWI}_{j}=r_{\mathrm{d}, j} \times P_{j, \text { net,imp }}$,

where $\mathrm{VWWI}_{j}$ is the net inflow of virtual water discharge in an industry $j$ and $P_{j \text {,net,imp }}$ is the net import volume of a commodity (service) in an industry $j$ (CNY 10,000).

\subsection{Input-occupancy-output structure model and model characteristics for urban water}

Economic and domestic water, together with ecological water and environmental water (i.e., wastewater dilution), must be considered in the study of rational water resource allocation to ensure a beneficial cycle and sustainable utilization of the water resource to meet the goal of restoring and rebuilding the environment. The process of constructing a water demand and water pollutant inventory system in the City of Chongqing consisted of four steps (Fig. 2). First, during database building, data on water, industries, and population are acquired. Second, input parameters are set with respect to industries and households. Third, a model is developed for calculating water demand and water pollutant discharge from industries and households; the industry model is based on an input-output analysis model. In the final step, the results are verified and the structure of water demand and water pollutants in the wastewater is evaluated. This system has the following features (Fig. 2):

(a) Provides an inventory on a local scale for the City of Chongqing by means of an input-output table as the first step for developing a basin unit-emission inventory;

(b) Develops a methodology and model based on an input-output table as a tool for creating an emission inventory to calculate water demand and water pollutant discharge in wastewater;

(c) Estimates the water demand and water pollutants of not only industry but also household, agriculture, forestry, livestock, and fishery as non-point sources;

(d) Corrects the data, especially the parameter setting, and attempts to verify the results.

\section{Case analysis in Chongqing}

\subsection{Database for input-occupancy-output table for water resources}

Because survey data are available for every stage of tabulation, it is difficult to ensure consistency in data processing methods and to coordinate data from various sources. To overcome this problem, this paper presents a mixed tabulation flow to prepare an input-occupancy-output table for water resources in Chongqing.

Given time and expenditure limitations, the table was prepared based on all available relevant statistics and the existing input-occupancy-output tables that adopt a mixed tabulation method; however, these are of lower accuracy and quality compared with large-scale survey data. In addition, the water resource statistics differ by sector and from the State Statistical Bureau in terms of standards and values, and some data are lacking or are of questionable accuracy. The advantage of this methodology is that the Urban Ecological Program team of the Chinese Academy of Social Sciences carried out a large-scale sampling survey in Chongqing in 2011 and obtained substantial data conducive to tabulation. 


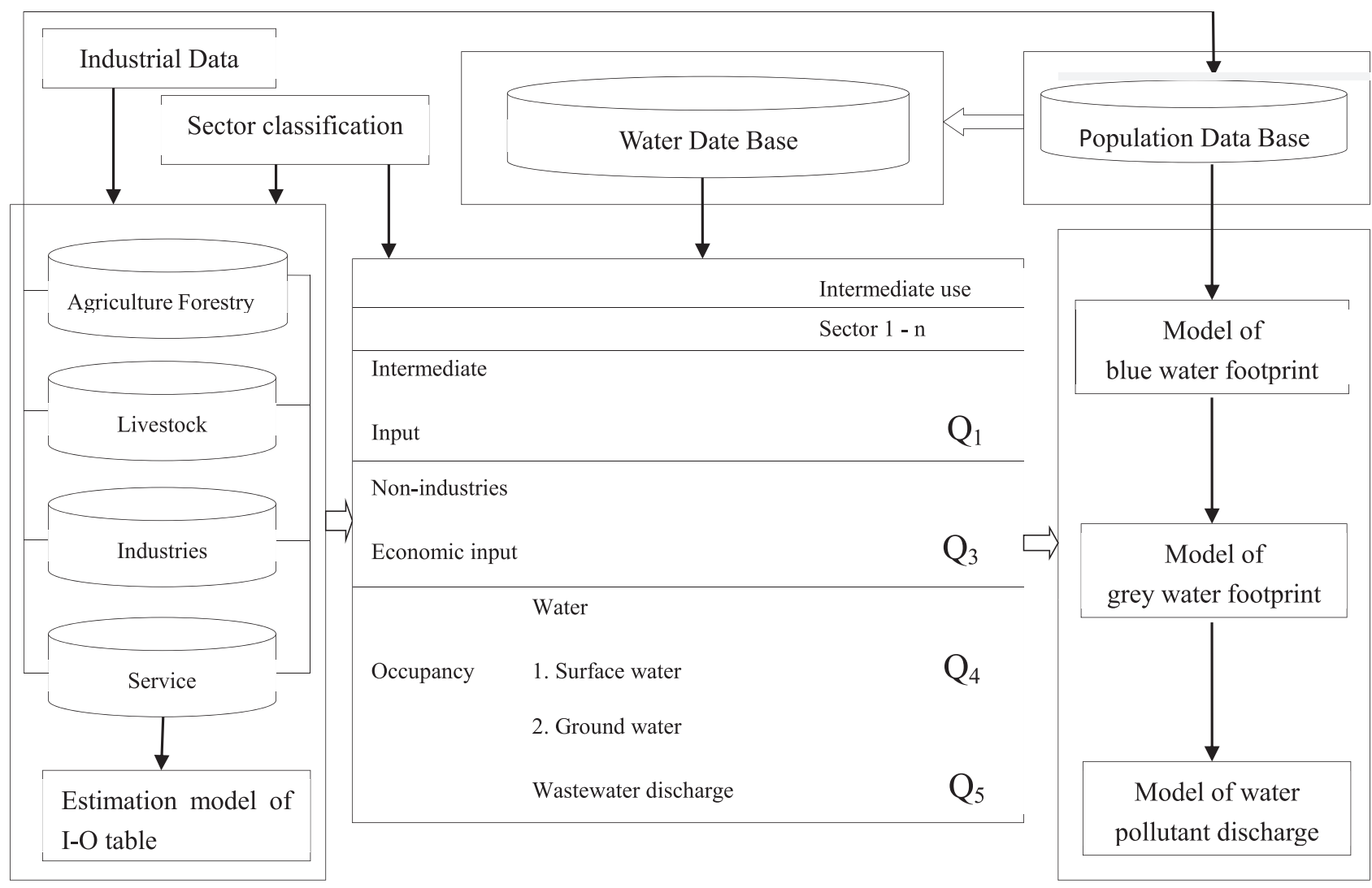

Fig. 2. The coupled relation between water demand and water pollutant inventory.

\subsection{Tabulation flow for an input-occupancy-output table for water resources}

The input-occupancy-output table for Chongqing's water resources for 2012, which is used in this paper, is primarily based on the Biproportional Scaling Method (RAS) for modification of the constant primary coefficient (i.e., mixed method). The detailed steps used are as follows:

(a) The region nearest to the study area is selected for the reference table based on reference tables used for input-output tables in similar regions. The study area and reference table should be similar in terms of industrial structure and economic structure. Because there is currently no available input-output table for water resources, the input-output table in Chongqing was selected as the reference table based on the above criteria.

(b) The sums of the rows and of the columns of the intermediate input matrix in the study area are taken as control variables (i.e., the general input-output quantity of all sectors is subject to advance control to minimize error).

(c) The data from departments with a great influence on water resources in Chongqing Municipality are collected and collated.

(d) The known coefficient and constant primary coefficient are determined based on practical situations within the study area. The position of the input coefficient, which is calculated based on the available data, is fixed in advance (i.e., the value is set to zero, and the values at both ends of the row and column in the input-output table are subject to subtraction). The primary coefficient is determined in the same manner but is obtained by the input-output primary coefficient identification method.

(e) The Biproportional Scaling Method (RAS Method) is used for calculation

\subsection{Principle of sector classification for the input-output table for} water resources

To reflect the actual situation of sectors related to water resources and to reduce the workload of tabulation, all sectors associated with water resource consumption are utilized, with the main sectors remaining separate and the secondary sectors combined. Sector classification is the basis for the input occupancy-output table, but the scope of the input-occupancy-output table is dependent on the extent of sector classification. The following factors are taken into consideration to determine the applicable classification method and the suitable number of sectors (Table 2):

(a) The existing statistical standard is observed to the greatest possible extent to utilize the most existing statistics. During the tabulation process, the entire body of data for these sectors is collected to the greatest extent possible, providing a large data set for tabulation after proper collation.

(b) The convenience of application is taken into consideration as much as possible to separate sectors with high water consumption from those with low water consumption. For example, in the balanced development of light industry and heavy industry, light industry is separated from heavy industry for tabulation across sectors, and light industry and heavy industry are also separated within a sector. 
Table 2

Departmental classification of the input-occupy-output table of water resources.

\begin{tabular}{|c|c|c|c|}
\hline No & Sector & No & Sector \\
\hline 1 & Agriculture & 13 & Chemicals \\
\hline 2 & Forestry & 14 & Non-metallic mineral production \\
\hline 3 & Animal husbandry & 15 & Metal smelting and rolling \\
\hline 4 & Fisheries & 16 & General and special-purpose machinery \\
\hline 5 & Coal mining and washing & 17 & Electronic machinery and equipment \\
\hline 6 & Metal mining & 18 & Hotels and restaurants \\
\hline 7 & Non-metal and other mining & 19 & Petroleum processing, cooking, and nuclear fuel processing \\
\hline 8 & Food manufacturing and tobacco processing & 20 & Electricity, gas, and water production and supply \\
\hline 9 & Textiles & 21 & Construction \\
\hline 10 & Wood processing and furniture manufacturing & 22 & Transportation, storage, and postal services \\
\hline 11 & Paper, printing, stationery, and sporting goods & 23 & Other services \\
\hline 12 & Metal production & 24 & Households \\
\hline
\end{tabular}

(c) The difficulty of data collection is also taken into consideration to address the ecological and economic features of the study area to the greatest extent possible. The sensitive and key industries involved in the study area are subject to classification in detail, whereas the minor industries in the study area are subject to minimal classification.

(d) The input-output table for 42 departments released by the Chongqing Statistical Department is taken as a reference. Based on this table as well as the actual condition of the research area, 42 departments are merged into 24 departments.

(e) Given the characteristics of the input-output table for water resources, some departments are considered special departments (i.e., some departments are subject to classification in detail, while some departments are subject to merger)

In this study, the key industries in Chongqing were determined, including four pillar industries. Based on the classification system given in the national input-output table, primary industry contains four departments, secondary industry contains 14 departments, and tertiary industry contains five departments. For this study, the household was considered an individual sector such that the four sectors involved in the discussion of consumption are primary industry, secondary industry, tertiary industry, and household.

\section{Results}

\subsection{Blue water and grey water composition}

The total water demand in the City of Chongqing, as determined in this study, was 576.76 billion $\mathrm{m}^{3}$, which approaches

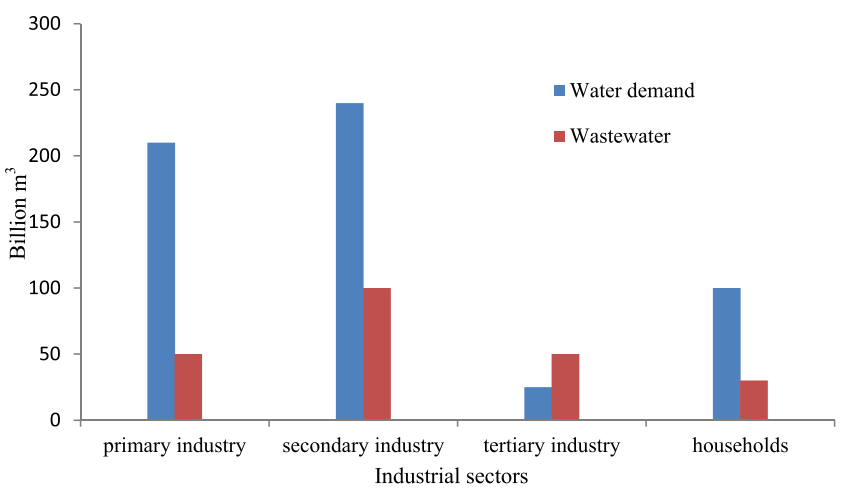

Fig. 3. Blue water and grey water composition in Chongqing. the result for water demand. In the industrial structure, water consumption in primary industries was second, accounting for $37 \%$. This was followed by secondary industry (42\%), tertiary industry (4\%), and households (17\%). Among industries, water consumption in secondary industries was highest, followed by primary industries, then tertiary industries. Household water consumption plays an important role in total water consumption, accounting for $17 \%$ of total blue water consumption (Fig. 3).

The pattern was similar for wastewater, with a total wastewater discharge of 242.24 billion $\mathrm{m}^{3}$. The discharge from primary industries was 58.14 million tons, accounting for $24 \%$ of the total discharge; this was surpassed by the discharge from secondary industries (104.16 billion tons; $42.99 \%$ of total discharge). The discharge was less from tertiary industries (46.03 billion tons, accounting for $19 \%$ of the total discharge) and households (33.91 billion tons, accounting for $13.99 \%$ of total discharge).

\subsection{Blue water footprint consumption structure}

The majority of industries in Chongqing exhibited indirect water usage, with only five industries with direct water utilization in excess of total water utilization: agriculture $\left(86.51\right.$ billion $\left.\mathrm{m}^{3}\right)$, forestry ( 40.37 billion $\mathrm{m}^{3}$ ), animal husbandry ( 57.77 billion $\mathrm{m}^{3}$ ), fisheries $\left(28.84\right.$ billion $\mathrm{m}^{3}$ ), and households (57.3 billion $\mathrm{m}^{3}$ ) (Fig. 4). Ten out of 24 industries had a total water utilization in excess of 100 billion $\mathrm{m}^{3}$, including agriculture; animal husbandry; food manufacturing and tobacco processing; wood processing and furniture manufacturing; chemical industry; electronic machinery and equipment; hotels and restaurants; electricity, gas, and water production and supply; construction; and households. Other industries ranged from 50 billion to 80 billion $\mathrm{m}^{3}$ in total water utilization. The annual average blue water footprint resulting from direct water consumption by residents was 101 billion $\mathrm{m}^{3}$. This result indicates that the consumption of commodities and services by residents plays a leading role in the blue water consumption footprint.

\subsection{Grey water footprint consumption structure}

The total grey water footprint discharge in the city was 242.24 billion tons. Of this, the industrial wastewater discharge was 109.68 million tons and the annual average grey water footprint resulting from wastewater discharge by residents was 36.5 billion tons (based on standard class III water). The annual average indirect grey water resulting from water discharge was 917.24 billion tons, thereby accounting for a larger portion of the grey water footprint. Among industries, food manufacturing and tobacco processing had the highest annual average grey water discharge, with up to 105.3 


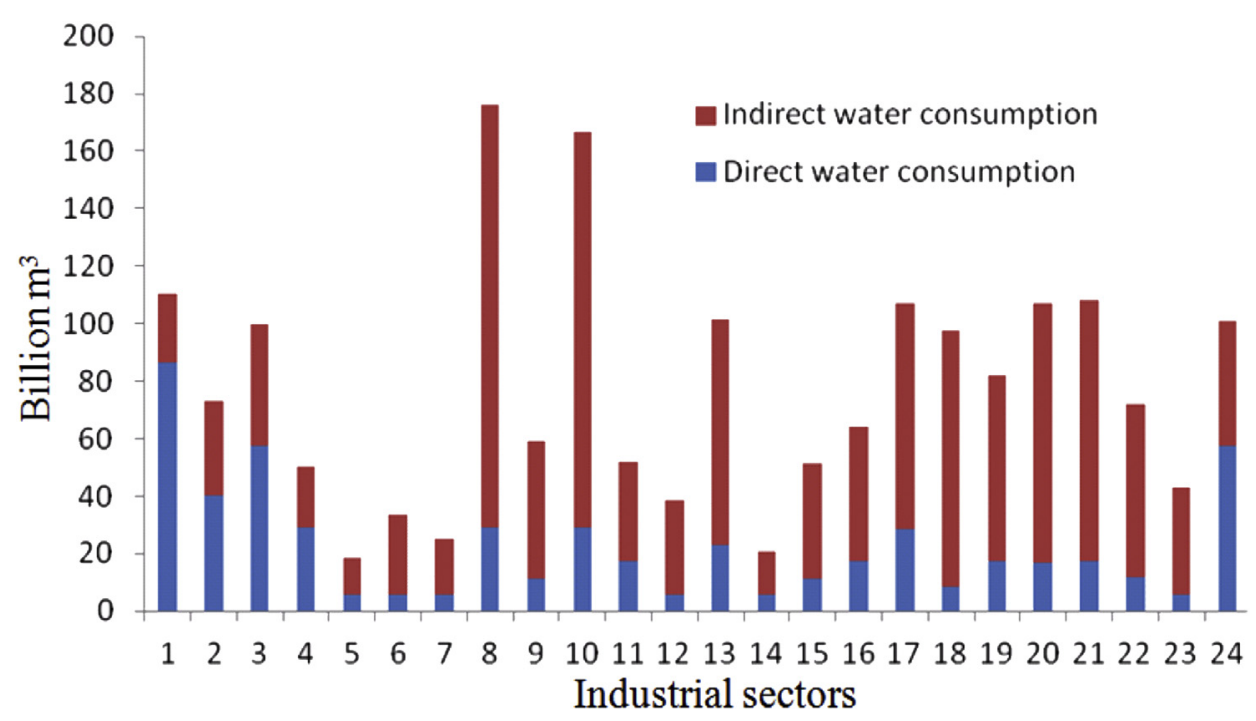

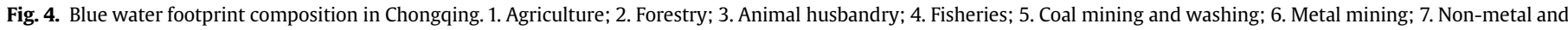

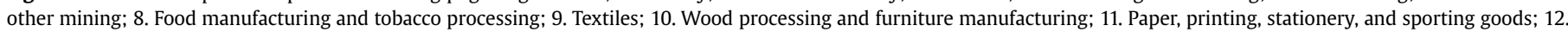

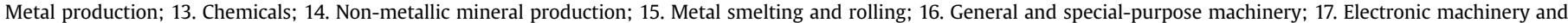

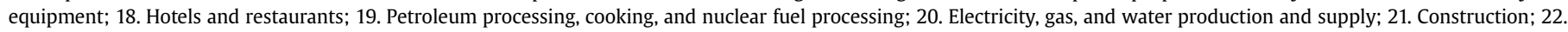
Transportation, storage, and postal services; 23. Other services; 24. Households.

billion $\mathrm{m}^{3}$, accounting for $11.37 \%$ of the total grey water discharge; this was followed by wood processing and furniture manufacturing (up to 78.2 billion $\mathrm{m}^{3}$ ). The grey water discharge from the forestry and fishery industries was very low, accounting for less than $1.1 \%$ (Fig. 5).

\subsection{Consumption demand and the blue water footprint}

The final consumption demand and the pertinent water footprint are shown in Table 3 . The consumption demand in primary industries was CNY 940.01 billion, accounting for only $8.2 \%$ of the total demand in the city. The local output was 1.5 times the external output, but the water footprint in the industry was up to 319 billion $\mathrm{m}^{3}$, accounting for $30.82 \%$ of the total water footprint in the city. The consumption demand in secondary industries was CNY 6172.33 billion, accounting for $53.66 \%$ of the city's total demand. The local output was 3.1 times the external quantity supplied, and its total water footprint was 347.2 billion $\mathrm{m}^{3}$, accounting for $33.54 \%$ of the city's total water footprint. The consumption demand in tertiary industries was CNY 4346.66 billion, accounting for 37.93\% of the total demand in the city. The local output was approximately 14 times the external quantity supplied, and its total water footprint was 369 billion $\mathrm{m}^{3}$, accounting for $35.64 \%$ of the city's total demand (Table 3).

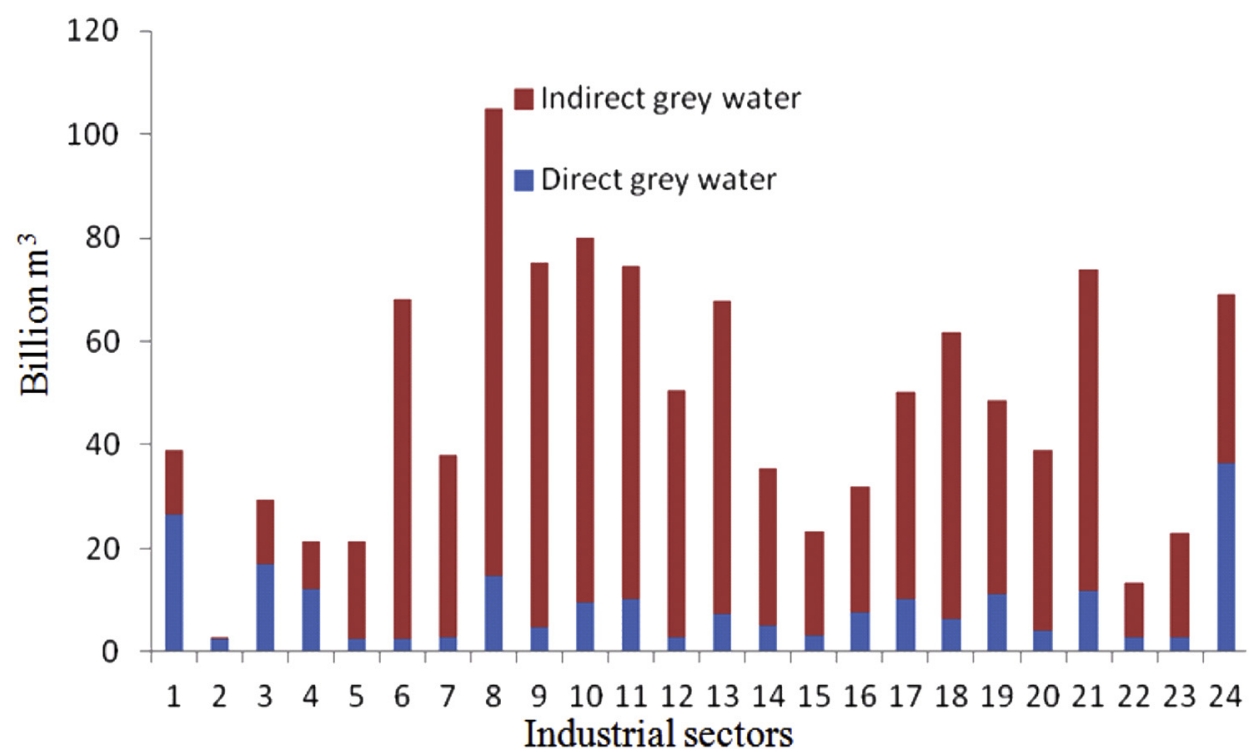

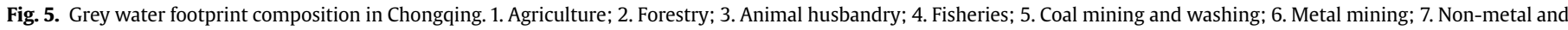

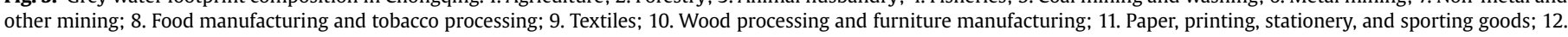

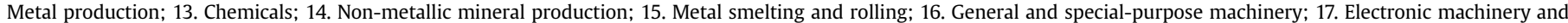

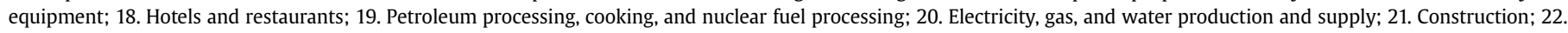
Transportation, storage, and postal services; 23. Other services; 24. Households. 
Table 3

Final consumption and water footprint in Chongqing.

\begin{tabular}{|c|c|c|c|c|c|c|}
\hline \multirow[t]{2}{*}{ Sector } & \multicolumn{3}{|c|}{ Amount (CNY $10^{9} /$ year) } & \multicolumn{3}{|c|}{ Proportion (\%) } \\
\hline & Local & External & Total & Local & External & Total \\
\hline \multicolumn{7}{|l|}{ Final consumption } \\
\hline Primary sectors & 632 & 308.01 & 940.01 & 5.5 & 2.7 & 8.2 \\
\hline Secondary sectors & 4123 & 2049.33 & 6172.33 & 35.98 & 17.68 & 53.66 \\
\hline Tertiary sectors & 3124 & 1222.66 & 4346.66 & 27.27 & 10.66 & 37.93 \\
\hline \multicolumn{7}{|l|}{ Water footprint } \\
\hline Primary sectors & 213 & 106 & 319 & 25.58 & 10.24 & 30.82 \\
\hline Secondary sectors & 248 & 99.2 & 347.2 & 23.94 & 9.6 & 33.54 \\
\hline Tertiary sectors & 23 & 346 & 369 & 2.2 & 33.44 & 35.64 \\
\hline
\end{tabular}

\section{Discussion}

\subsection{Review of the tabulation method}

The ecological input-occupancy-output table is characterized by two parts-input and occupancy-composed of natural resources, including land (e.g., arable land, water surface, meadow), water, forest and minerals, to study the relationship between flow and inventory. In addition, water used for ecological purposes is considered a water resource in order to study the relationship between the economic sector and the water needs of the ecological environment (Setola et al., 2009). Although in many ways similar to the work of Chen et al. (1992), the study presented here has a different focus. While Chen and colleagues paid more attention to the relationship between the flow and stock of the economic system (Chen et al., 1992), the emphasis in the current study is on the relationship between the flow and stock of the economic system and the ecological system (Xiao et al., 2011) and further develops Chen's input-occupancy-output technique.

Modelling is based on a series of assumptions; there is no exception to the simple input-output model. Modelling of the ecological system is complex, and its accuracy is principally related to the preparation method and the tailoring of coefficients. However, the extensive application of simplistic models has resulted in increasing discord between assumptions and reality (Wiedmann et al., 2007), with one or several assumptions in different application areas violating the practical situation. To make the analysis results more reliable, various correction models have been presented to rectify the contradiction between assumption and reality (Tan et al., 2012). Because production techniques and economic structures differ, there is a significant difference in the direct consumption coefficient; however, the direct consumption coefficient is at the core of the input-output theory. Consequently, there are many tabulation methods for the input-output table. The present study discusses a mixed tabulation method for use by common research personnel to tabulate input-occupancy-output for water resources in Chongqing.

The surveys used to fill gaps in existing secondary data can be very costly. Thus, various methods have been applied to derive these tables from their national counterparts using all information available about a regional economy. Although this approach may not be ideal, it makes use of the best available data. In addition, the information used to create the input-output table applies to a given point in time; it provides only a snapshot of the economic system at a certain moment and therefore represents a static analysis of the system (Velázquez, 2006). In future research, the ecological input-occupancy-output table should focus on the relationship between the social water cycle and blue water as well as grey water. Research should include (1) the coupling and functional mechanism of the social water cycle and the natural water cycle, thereby identifying an objective foundation for the regulation and management of the social water cycle; (2) a mechanism to allow for evolution of the social water cycle system, water volume, and water quality, thereby clarifying the basic process and key links in the regulation and management of the social water cycle; and (3) a decision-making mechanism for the regulation and demand management of the social water cycle.

\subsection{The blue and grey water footprints}

Blue and grey water are highlighted in this study. One of the key points in calculating the blue water footprint is clarifying the actual consumption. Because the calculation of blue water is more precise in the present study, water discharged from the production system is not listed as product water consumption when examining the relationship between water utilization and water consumption. However, the various blue waters consumed in different sectors and industries are considered identical, which fails to take into consideration the difference in water quality between various industries or different regions (Vanham et al., 2013; Wang et al., 2013). From this perspective, the results for the blue water footprint fail to fully reflect the practical situation; the differences in the quality of water used by different industries or regions only reveal different water supply conditions and fail to reflect disparities in the national economic structure, production level, and consumption scale. Therefore, it is reasonable to assume that the blue water in various regional sectors is identical (Wang et al., 2009; Wichelns, 2015).

The consumption demand in primary industries and the water footprint are in striking contrast, namely regarding the lower demand for products. However, water resource consumption by product is very large, reflecting a lower product value in the industry and a failure to embody the water resource value; this is counter to the water resource protection and conservation. In contrast, the consumption demand in tertiary industries is higher, with lower water resource consumption by the product or service; this result indicates that tertiary industries have a greater water utilization efficiency. Secondary industries have a greater water utilization efficiency compared to primary industries, although the external supply of secondary industries is a small percentage given the higher virtual water content of input products; therefore, the corresponding water footprint constitutes a larger percentage. Thus, to leave the consumption demand unchanged, Chongqing must curtail its urban output percentage or constrain the development of industry. The consumption demand in tertiary industries can be expanded by the selective input of products with a higher virtual water content in secondary industries to reduce local water resource consumption and alleviate water resource pressure.

Blue water consumption is influenced by two factors: the complete water consumption coefficient and the total amount of consumption. The total amount of consumption reflects the commodity service consumption structure, while the complete water consumption coefficient is associated with direct water consumption and the industrial chain, reflecting the influence of technological level and industrial structure on the water footprint (Zhang and Anadon, 2014). Analysis of the complete water consumption coefficient across industries shows the largest value for agriculture, followed by the food, beverage, and tobacco industries. However, there is no noticeable variance in the complete water consumption coefficient among mechanical equipment manufacturing, transportation, storage, and the postal services, information transmission, computer service and software industry.

Grey water discharge is influenced by three factors: the conversion coefficient for grey water, the complete water discharge coefficient, and the total amount of consumption (Wiedmann et al., 2007; Zhi et al., 2015). The total amount of consumption reflects the 
commodity service consumption structure. The complete water consumption coefficient is associated with direct water discharge and the industrial chain, thereby reflecting the influence of the technological level and industrial structure on the grey water footprint. The conversion coefficient for grey water is associated with pollutant concentration, water quality standard, and pollutant background concentration, indicating the influence of the commodity service production process, environment quality requirements, and the current situation on the grey water footprint.

The grey water footprint differs from the blue water footprint in that the focus is on the variance in water quality. Because many substances have different assessment indicators related to water quality, the substances contained in the water discharged from different industries differ in their type and concentration. In this study, the gross amount is used as the assessment indicator and is in line with other water environmental studies in China that have focused on the gross amount. Although the background values of water pollutants in different regions vary, we have ignored the influence of background levels and assumed that the background is pollution-free. In addition, the permissible pollutant load for a water body is influenced to a certain extent by human factors; in this study, the preliminary estimate of the grey water footprint is based on standard values of various water quality parameters defined in the quality standard for the water environment. Based on the above criteria, the grey water footprint estimate should be low compared with the real-world situation.

\subsection{Demand for the consumption and utilization of water resources}

As indicated by the ecological input-occupancy-output model, the water resource input amount is subject to four factors when the gross amount of water resources is limited: production structure, final demand structure, intermediate input structure, and the intensity of water resource utilization. Therefore, the discussion regarding the establishment of a water resource rational allocation system in Chongqing is based on adjustments and enhancements of these four factors.

The ecological input-occupancy-output model is, to a certain extent, a demand-pull model; consumption, investment, and export in the model are exogenous factors. With a constant input structure, the production structure is dependent on final demand; if final demand remains unchanged, the production structure has no means of change. Thus, it is more meaningful and fundamental to optimize water resource allocation based on final demand rather than on the production structure.

Practically speaking, it is difficult to optimize water resource structure by changing the final demand structure. Household consumption depends on daily needs, and the demand for water is related to consumer preference and does not change merely due to a change in the water demand of a product in a sector. Therefore, consumer preference is likely to come into conflict with a limited water resource and will result in a series of institutional problems beyond the scope of this paper. It would be practical to include corresponding institutional arrangements based on practical situations and planning targets for a local water resource, such as a cumulative charge for water resources, in the decision-making process within local departments.

\section{Conclusions}

Our research indicated that the total water demand in the City of Chongqing in 2012 was 576.76 billion $\mathrm{m}^{3}$ and that the total wastewater discharge was 242.24 billion $\mathrm{m}^{3}$. Final consumption demand and the pertinent water footprint revealed that if the consumption demand is left unchanged, Chongqing will curtail its urban output percentage (or constrain the development of industry) and a product with a higher virtual water content in a secondary industry will be subject to selective inputs. However, in a tertiary industry, the consumption demand will expand to reduce local water resource consumption and alleviate pressure on the water resource. An effective industrial water resource administrative policy and system are essential in solving distribution conflicts.

With the various effects from the natural condition of the water resources, economic social scale, development stage, global climate change, and other factors, Chongqing is confronted with water source supply conflicts, water pollution, ecological degradation, and other serious problems. Local governments have made great progress in protecting water resources and achieving an effective distribution for each field in the economic system. Our study suggests that to achieve an effective scientifically regulated social water system, we must control excessive development and utilization of water resources and address ecological and environmental issues caused by socioeconomic water consumption exceeding ecological water use.

In Chongqing, research on the city's future resources should be based on the following: (1) Water resource allocation cannot be limited to satisfying the balance between supply and demand regarding water resource quantity but must realize a balance between regional development and various factors related to water, including water quality, water and soil, and water ecology. (2) The overall problems of blue water, green water, and virtual water should be addressed not just on the basis of discussions about blue water but as key points and hot fields of social water circulating research; (3) Social water circulating regulation and demand management policy can be used as the basis for measure and approach selection in regulating social water circulation and management.

\section{Acknowledgements}

This work was supported by the Key Supporting Project of the Ministry of Science and Technology of China (2007BAC28B04, RCYJ20110006). We thank Denise Rennis for his help in writing this paper and the journal's editors and anonymous reviewers for their comments on an earlier version of this manuscript.

\section{References}

Aviso, K.B., Tan, R.R., Culaba, A.B., Cruz Jr., J.B., 2011. Fuzzy input-output model for optimizing eco-industrial supply chains under water footprint constraints. J. Clean. Prod. 19, 187-196.

Bernardo, M., 2014. Integration of management systems as an innovation: a proposal for a new model. J. Clean. Prod. 82, 132-142.

Bortolini, M., Cascini, A., Gamberi, M., Mora, C., Regattieri, A., 2014. Sustainable design and life cycle assessment of an innovative multi-functional haymaking agricultural machinery. J. Clean. Prod. 82, 23-36.

Cao, S., 2012. Why China's approach to institutional change has begun to succeed. Econ. Model. 29, 679-683.

Cao, S., Li, S., Ma, H., Sun, Y., 2015. Escaping the resource curse in China. Ambio 44,1-6.

Cao, S., Lv, Y., Zheng, H., Wang, X., 2014a. Challenges facing China's unbalanced urbanization strategy. Land Use Policy 39, 412-415.

Cao, S., Lv, Y., Zheng, H., Wang, X., 2014b. Research of the risk factors of China's unsustainable socioeconomic development: lessons for other nations. Soc. Indic. Res. 1-11.

Carballo Penela, A., Sebastián Villasante, C., 2008. Applying physical input-output tables of energy to estimate the energy ecological footprint (EEF) of Galicia (NW Spain). Energy Policy 36, 1148-1163.

Chang, Y., Ries, R.J., Wang, Y., 2010. The embodied energy and environmental emissions of construction projects in China: an economic input-output LCA model. Energy Policy 38, 6597-6603.

Chen, G.Q., Chen, Z.M., 2010. Carbon emissions and resources use by Chinese economy 2007: a 135-sector inventory and input-output embodiment. Commun. Nonlin. Sci. Numer. Simul. 15, 3647-3732.

Chen, G.Q., Chen, Z.M., 2011. Greenhouse gas emissions and natural resources use by the world economy: ecological input-output modeling. Ecol. Model. 222, 2362-2376. 
Chen, L., Cao, S., 2013. Lack of integrated solutions hinders environmental recovery in China. Ecol. Eng. 54, 233-235.

Chen, P.-C., Crawford-Brown, D., Chang, C.-H., Ma, H.-W., 2014. Identifying the drivers of environmental risk through a model integrating substance flow and input-output analysis. Ecol. Econ. 107, 94-103.

Chen, X., Cao, J., Xue, X., Lu, Z., 1992. Input-Occupancy-Output Analysis of the Urban and Rural Economies of China. Science Press, Beijing.

Chen, X., Yang, C., Xu, J., 2002. Water conservancy economy input-occupancy-output table of China and its application. Int. J. Dev. Plan. Literature 17, 19-28.

Chen, Z.M., Chen, G.Q., Zhou, J.B., Jiang, M.M., Chen, B., 2010. Ecological input-output modeling for embodied resources and emissions in Chinese economy 2005. Commun. Nonlin. Sci. Numer. Simul. 15, 1942-1965.

Cheng, E.W., Chiang, Y.H., Tang, B.S., 2006. Exploring the economic impact of construction pollution by disaggregating the construction sector of the input-output table. Build. Environ. 41, 1940-1951.

Dias, A.C., Lemos, D., Gabarrell, X., Arroja, L., 2014. Environmentally extended input-output analysis on a city scale - application to Aveiro (Portugal). J. Clean. Prod. 75, 118-129.

Dongjing, C., Peiying, L., Zeyu, H., Qiang, C., 2005. Analysis of natural resource multipliers based on input-occupancy-output technique. Ecol. Econ. 10, 007.

Druckman, A., Jackson, T., 2009. The carbon footprint of UK households 1990-2004 a socio-economically disaggregated, quasi-multi-regional input-output model. Ecol. Econ. 68, 2066-2077.

Duarte, R., Sánchez-Chóliz, J., Bielsa, J., 2002. Water use in the Spanish economy: an input-output approach. Ecol. Econ. 43, 71-85.

García Morillo, J., Rodríguez Díaz, J.A., Camacho, E., Montesinos, P., 2015. Linking water footprint accounting with irrigation management in high value crops. J. Clean. Prod. 87, 594-602.

Grêt-Regamey, A., Kytzia, S., 2007. Integrating the valuation of ecosystem services into the input-output economics of an Alpine region. Ecol. Econ. 63, 786-798.

Guan, D., Hubacek, K., 2008. A new and integrated hydro-economic accounting and analytical framework for water resources: a case study for North China. J. Environ. Manag. 88, 1300-1313.

Guan, L., Sun, G., Cao, S., 2011. China's bureaucracy hinders environmental recovery. AMBIO J. Hum. Environ. 40, 96-99.

Jenerette, G.D., Wu, W., Goldsmith, S., Marussich, W.A., John Roach, W., 2006 Contrasting water footprints of cities in China and the United States. Ecol. Econ. 57, 346-358.

Jeswani, H.K., Azapagic, A., 2011. Water footprint: methodologies and a case study for assessing the impacts of water use. J. Clean. Prod. 19, 1288-1299.

Jiang, Z., Tan, J., 2013. How the removal of energy subsidy affects general price in China: a study based on input-output model. Energy Policy 63, 599-606.

Liang, S., Wang, C., Zhang, T., 2010. An improved input-output model for energy analysis: a case study of Suzhou. Ecol. Econ. 69, 1805-1813.

Liang, S., Zhang, T., 2012. Comparing urban solid waste recycling from the viewpoint of urban metabolism based on physical input-output model: a case of Suzhou in China. Waste Manag. 32, 220-225.
Lin, C., 2009. Hybrid input-output analysis of wastewater treatment and environmental impacts: a case study for the Tokyo Metropolis. Ecol. Econ. 68, 2096-2105.

Liu, H.-T., Guo, J.-E., Qian, D., Xi, Y.-M., 2009. Comprehensive evaluation of household indirect energy consumption and impacts of alternative energy policies in China by input-output analysis. Energy Policy 37, 3194-3204.

Miao, C., Ashouri, H., Hsu, K.-L., Sorooshian, S., Duan, Q., 2015. Evaluation of the PERSIANN-CDR daily rainfall estimates in capturing the behavior of extreme precipitation events over China. J. Hydrometeorol. 16, 1387-1396.

Setola, R., De Porcellinis, S., Sforna, M., 2009. Critical infrastructure dependency assessment using the input-output inoperability model. Int. J. Crit. Infrastruct. Prot. 2, 170-178.

Tan, R.R., Aviso, K.B., Barilea, I.U., Culaba, A.B., Cruz Jr., J.B., 2012. A fuzzy multiregional input-output optimization model for biomass production and trade under resource and footprint constraints. Appl. Energy 90, 154-160.

Vanham, D., Mekonnen, M.M., Hoekstra, A.Y., 2013. The water footprint of the EU for different diets. Ecol. Indic. 32, 1-8.

Velázquez, E., 2006. An input-output model of water consumption: analysing intersectoral water relationships in Andalusia. Ecol. Econ. 56, 226-240.

Wang, S., Yang, F.-L., Xu, L., Du, J., 2013. Multi-scale analysis of the water resources carrying capacity of the Liaohe Basin based on ecological footprints. J. Clean. Prod. 53, 158-166.

Wang, Y., Xiao, H.L., Lu, M.F., 2009. Analysis of water consumption using a regional input-output model: model development and application to Zhangye City, Northwestern China. J. Arid Environ. 73, 894-900.

Wichelns, D., 2015. Virtual water and water footprints do not provide helpful insight regarding international trade or water scarcity. Ecol. Indic. 52, 277-283.

Wiedmann, T., Lenzen, M., Turner, K., Barrett, J., 2007. Examining the global environmental impact of regional consumption activities-part 2: review of input-output models for the assessment of environmental impacts embodied in trade. Ecol. Econ. 61, 15-26.

Xiao, Q., Gao, Y., Hu, D., Tan, H., Wang, T., 2011. Assessment of the interactions between economic growth and industrial wastewater discharges using cointegration analysis: a case study for China's Hunan Province. Int. J. Environ. Res. Public Health 8, 2937-2950.

Xikang, C., 2000. Shanxi water resource input-occupancy-output table and its application in Shanxi Province of China. In: XIII International Conference on Input-Output Techniques, Macerata, Italy.

Zhang, C., Anadon, L.D., 2014. A multi-regional input-output analysis of domestic virtual water trade and provincial water footprint in China. Ecol. Econ. 100, 159-172.

Zheng, H., Wang, X., Cao, S., 2014. The land finance model jeopardizes China's sustainable development. Habitat Int. 44, 130-136.

Zhi, Y., Yang, Z.F., Yin, X.N., Hamilton, P.B., Zhang, L.J., 2015. Using gray water footprint to verify economic sectors' consumption of assimilative capacity in a river basin: model and a case study in the Haihe River Basin, China. J. Clean. Prod. 92, 267-273. 